\title{
Photon- or $\gamma$-Induced Paramagnetic Defects in Polycrystalline and Glassy Metaphosphates Containing Nitrogen
}

\author{
Yuichi WATANABE, Takafumi KANAZAWA and Hiroshi KAWAZOE* \\ Department of Industrial Chemistry, Tokyo Metropolitan University \\ 2-1-1, Fukasawa, Setagaya-ku, Tokyo 158 \\ * Department of Inorganic Materials, Tokyo Institute of Technology
}

\begin{abstract}
UV-, X-or $\gamma$-irradiated phosphate glasses and polycrystalline metaphosphates both containing a small amount of nitrogen showed a complex ESR absorption characterized by the lineshape of 5-line. The absorption was analyzed using isotope enrichments $\left({ }^{15} \mathrm{~N}\right.$ and $\left.{ }^{2} \mathrm{D}\right)$ and $\mathrm{K}$-band measurements and found to be constructed by the anisotropic $\widetilde{g}$-tensor $\left(g_{x}=2.0087, g_{y}=2.0047\right.$, $\left.g_{z}=2.0039\right)$, the anisotropic $h f$ tensor due to a ${ }^{14} \mathrm{~N}\left(A_{x}=A_{y}=-0.2 \mathrm{mT}, A_{z}=3.6 \mathrm{mT}\right)$ and two isotropic hf interactions due to ${ }^{31} \mathrm{P}(A \cong 3.0 \mathrm{mT})$. The center was inferred to be a hole trapped on $\mathrm{N}$ (NHC) on the basis of the analysis. On irradiation with optical band gap light was found the simultaneous formation of $\mathrm{NHC}$ and a trapped electron on $\mathrm{P}$. This suggests that $\mathrm{N}$ acts as a donor on the UV-irradiation.

[Received February 18, 1985]
\end{abstract}

\section{窒素含有リン酸塩ガラス中の光誘起常磁性中心}

\author{
渡辺裕一・金澤孝文・川副博司* \\ $\left(\begin{array}{lll}\text { 東京都立大学 } & \text { 工学部 } & \text { 工業化学科 } \\ * \text { 東京工業大学 } & \text { 工学部 } & \text { 無機材料工学科 }\end{array}\right)$
}

\begin{abstract}
窒素を少量含有する多結晶及びガラス状メタリン酸塩中に紫外光又はガンマ線を照射した際に生 ずる常磁性欠陥中心を ESR を用いて調べた５個のシグナルよりなる吸収線を同位体濃縮法，K バンド測定より解析し, 異方性をもつ $\tilde{g}$ テンルと, ${ }^{14} \mathrm{~N}$ の異方性をもつ超微細構造, 2 個の ${ }^{31} \mathrm{P}$ の等 方的超微細構造がこの吸収を与えることが分った．更にこの欠鿇中心は酸素を置換した窒素が正孔 を捕獲して生成し，その構造として P-N-P 平面型が推定された。また光学ギャップ程度の紫外光 $(190 \mathrm{~nm} \sim)$ 照射で，窒素上の正孔捕獲中心とリン上の電子捕獲中心が同時に生成することから， 窒素がエレクトロン・ドナーとして働くことが分った。

(1985 年 2 月 18 日受付)
\end{abstract}

Key-words : Nitrogen in phoshates, Photon-induced ESR, Strengthening of glass network

\section{Introduction}

A small amount of nitrogen incorporated in oxide glasses affects remarkably their dynamic and static properties. Mechanical and chemical properties of oxynitride glasses have been investigated and the increases in density, $T_{\mathrm{g}}$, hardness, fracture toughness, elastic modulus and chemical durability have been found with increasing nitrogen content ${ }^{11}$. These changes in the properties suggest that chemical bond around nitrogen plays an important role in determining these properties; the incorporated nitrogen is supposed to form more highly crosslinked network than oxygen.

It has been found that when alkali silicate glasses are highly reduced and a small amount of nitrogen is contained in the glass, the glasses show photochromism². These glasses showed a strong absorption in ultra-violet region extending 
to longer wave-length and its intensity was proportional to the nitrogen content $^{3,4}{ }^{3}$. On an exposure of the glass to X-rays or ultra-violet light above $200 \mathrm{~K}$, it developed visible coloration and paramagnetism. It appears that these facts result from the incorporation of nitrogen, since the nitrogen free glasses are insensitive to the irradiation with ultra-violet light $t^{5}$.

In a present work we examine the role of the incorporated nitrogen in relation to the changes of the optical and mechanical, properties of metaphosphate glasses. A photon induced paramagnetic center associated with a nitrogen was used as a probe to elucidate local structure and electronic state around a nitrogen. A possible structural model of the center will be given by analyzing its ESR hyperfine structures and examining its thermal stability. A part of the results have appeared in a preliminary report ${ }^{6}$. The effect of nitrogen on the chemical and mechanical properties of oxynitride glasses will be discussed in terms of the covalent nature of $\mathrm{P}-\mathrm{N}$ bonds. The donor properties of nitrogen will be experimentally evidenced by detecting the simultaneous formation of a positive hole on a nitrogen and an electron center on a phosphorous atom.

\section{Experiments}

Glasses of the composition $50 \mathrm{Na}_{2} \mathrm{O} \cdot 50 \mathrm{P}_{2} \mathrm{O}_{5}$ (hereafter referred to as SMP) were prepared by melt-quenching method from a mixture of reagent grade $\mathrm{Na}_{2} \mathrm{CO}_{3}$ and $\mathrm{H}_{3} \mathrm{PO}_{4}\left(85 \%\right.$ in $\left.\mathrm{H}_{2} \mathrm{O}\right)$. Ammonia gas was bubbled into the melt with quartz tube to incorporate nitrogen into the glass. Polycrystalline samples were also prepared to obtain a well resolved ESR spectrum which was greatly helpful in analyzing the spectra. Polycrystalline SMP was obtained by crystallizing the mother glass at $350^{\circ} \mathrm{C}$ for $24 \mathrm{~h}$. Polycrystalline magnesium metaphosphate (hereafter referred to as MMP) was prepared by heating the mixture of reagent grade $\mathrm{MgO}$ and $\mathrm{NH}_{4} \mathrm{H}_{2} \mathrm{PO}_{4}$ up to $800^{\circ} \mathrm{C}$ for $24 \mathrm{~h}$. Nitrogen content of the SMP glasses was determined by the Kjeldahl method" and found to be 0.5 wt $\%$.

Isotope enrichment $\left({ }^{15} \mathrm{~N}\right)$, an effective method for identifying ESR centers, was carried out in some samples. Each sample was crushed and placed in a quartz tube. Each tube was evacuated, sealed and subjected to $\gamma$-irradiation from $\mathrm{a}^{60} \mathrm{Co}$ source with the total dose of $1 \mathrm{M}$ rad at $77 \mathrm{~K}$. X-ray $(35 \mathrm{kV}, 15 \mathrm{~mA}$ ) or UV (Xe lamp, Varian
VIX 300) irradiation was also conducted at room temperature or $77 \mathrm{~K}$ for some samples. X-band K-band ESR spectra were obtained on JEOL JES-PE JES-ME spectrometers. Applied magnetic field and microwave frequency were calibrated by a proton NMR marker and a cavity wave meter, respectively. Measurement of optical absorption spectrum in UV and visible region was made on Jasco UVIDEC 610C spectrometer.

\section{Results and discussion}

\section{1 Isolation of 5 -line spectrum}

After $\gamma$-irradiation at $77 \mathrm{~K}$, ESR measurements were carried out without intervening warm-up. Figure 1 shows an X-band spectrum of SMP glass. The spectrum was found to consist of four groups of lines from thermal bleaching. The inset of the figure shows the wide scan spectrum and we can see two sets of hyperfine (hf) doublets $\left(P_{1}\right.$ and $\left.\mathrm{P}_{2}\right)$, each due to ${ }^{31} \mathrm{P}$ nucleus $(\mathrm{I}=1 / 2, \mathrm{~N} . \mathrm{A}$. = $100 \%)$. The centers responsible for the doublets are phosphorous electron center (PEC $)^{8 i \sim 11}$. The relation between these two centers is that in $\mathrm{P}_{2}$ center an excess electron is considered to occupy the antibonding molecular orbital of $\mathrm{PO}_{4}$ tetrahedral group, whereas in $\mathrm{P}_{1}$ it is to locate on a nonbonding orbital of the phosphorus atom hav-
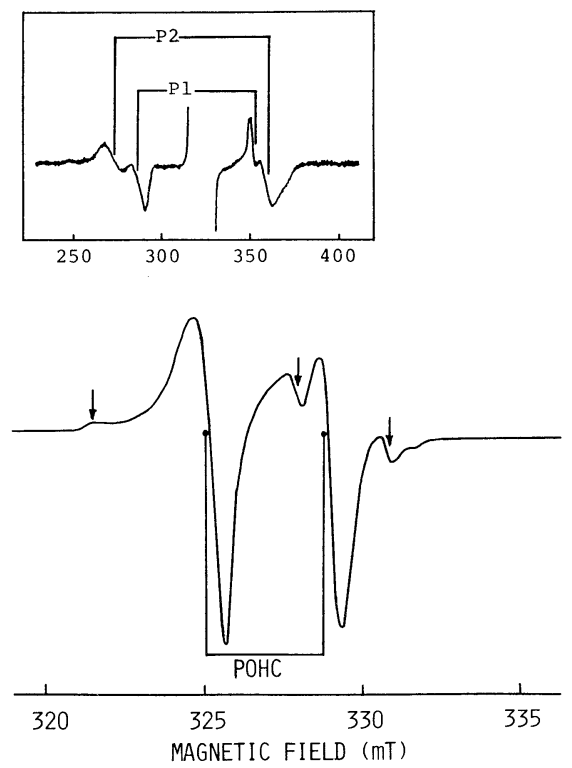

Fig. 1. X-band (9.196 GHz) ESR spectrum of nitrogencontaining sodium metaphosphate glass $\gamma$-irradiated and measured at $77 \mathrm{~K}$. The arrows indicate absorption of nitrogen associated hole center. The inset spectrum was obtained for wide scanning range and at high spectrometer gain. The labels $\mathrm{P}_{1}$ and $\mathrm{P}_{2}$ represent phosphorous electron centers (see text). 

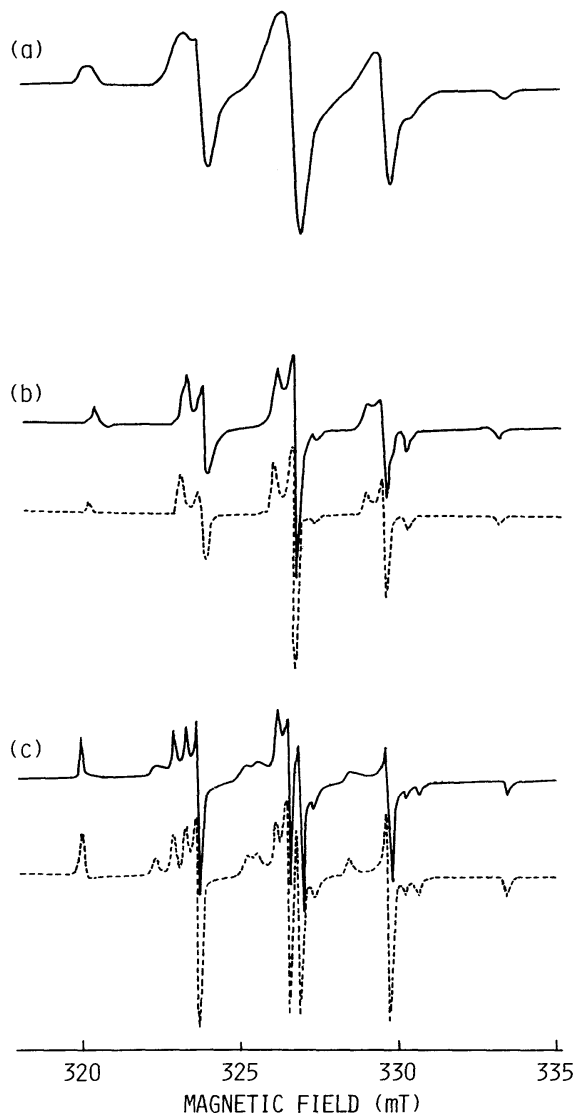

Fig. 2. X-band (9.442 GHz) ESR spectra of metaphosphates.

(a) Sodium metaphosphate glass; $\gamma$-irradiated at $77 \mathrm{~K}$ and annealed at $100^{\circ} \mathrm{C}$ for $2 \mathrm{~h}$.

(b) Polycrystalline sodium metaphosphate ; X-irradiated at $300 \mathrm{~K}$.

(c) Polycrystalline magnesium metaphosphate ; Xirradiated at $300 \mathrm{~K}$.

Measurements were carried out at $77 \mathrm{~K}$. Dashed lines in (b) and (c) are obtained by computer simulation. The parameters used in the calculations are listed in Table 2.

ing trigonal pyramidal or distorted tetrahedral coordination ; the coordination structure of $\mathrm{P}_{2}$ relaxes into $P_{1}$ by thermal annealing ${ }^{91,10)}$. The third paramagnetic species detected in Fig. 1 is $\mathrm{POHC}$, which is shown in the bottom as an hf doublet due to ${ }^{31} \mathrm{P}$ nucleus ${ }^{11-14}$. POHC lines were dominant in the bottom spectrum and it was difficult to reveal the detailed shape of the fourth absorption indicated by arrows.

$\mathrm{POHC}$ lines were completely bleached out by thermal annealing at $100^{\circ} \mathrm{C}$ for $2 \mathrm{~h}$ and the line shape of 5 -line spectrum was isolated clearly (Fig.2 (a)). This was obtained for the SMP glass prepared by $\mathrm{NH}_{3}$ gas bubbling. The five component lines in the figure were bleached out simultaneously by annealing at higher temperatures. This suggests that the five lines in the spectrum have the same origin. It has been proposed that a tetraphosphoric radical is responsible for the 5 -line spectrum, the five absorptions being hf structures due to four equivalent ${ }^{31} \mathrm{P}$ nuclei with intensity ratio of $1: 4: 6: 4: 1^{15)}$. Since only POHC signal was observed in the central field for nitrogen free glasses, the interpretation seems to be erroneous.

\subsection{Analysis of 5-line spectrum}

The spectra of X-irradiated polycrystalline SMP and MMP are shown in Fig. 2 (b) and (c), respectively, the polycrystalline SMP being prepared by crystallizing SMP glass containing nitrogen and $\mathrm{MMP}$ by using $\mathrm{NH}_{4} \mathrm{H}_{2} \mathrm{PO}_{4}$ as a raw material. Each spectrum showed an well resolved but rather complex line shape compared with that of the glass shown in Fig. 2 (a). It is noted that the characteristics of their line shape and resonance fields are almost similar, although linewidth of glass-spectrum is broader due to site to site structural distribution. It is likely that these spectra originate from the same kind of radical species.

Anisotropic $\widetilde{g}$-tensor and several anisotropic hf interactions are considered to contribute to the

Table 1. Stable isotopes having non zero nuclear spin.

\begin{tabular}{lcc}
\hline ISOTOPE & N.A(8) & $I^{2)}$ \\
\hline${ }^{14}{ }_{\mathrm{N}}$ & 99.64 & 1 \\
${ }^{15} \mathrm{~N}$ & 0.36 & $1 / 2$ \\
${ }^{31} \mathrm{P}$ & 100.00 & $1 / 2$ \\
${ }^{1} \mathrm{H}$ & 99.98 & $1 / 2$ \\
${ }^{2} \mathrm{D}$ & 0.02 & 1 \\
\hline 1) natural abundance \\
2) nuclear spin
\end{tabular}

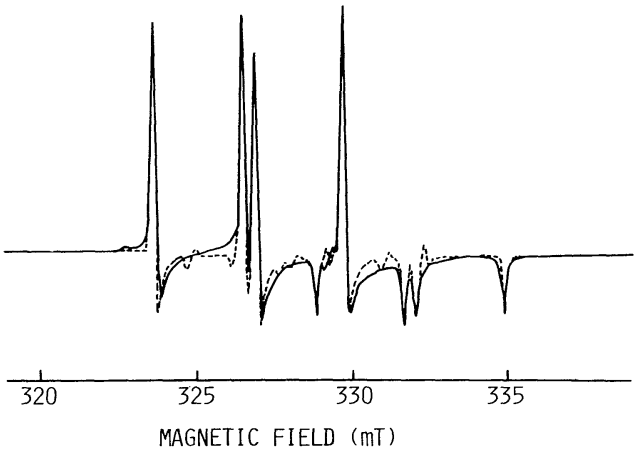

Fig. 3. X-band ESR spectrum of ${ }^{15} \mathrm{~N}$ enriched polycrystalline magnesium metaphosphate. The measurement was done at RT. Dashed line is obtained by computer simulation. 
apparent complexity of the crystal spectra. Possible elements which can give the hf structures are listed in Table 1. Isotope enrichments were carried out to assign the hf structures to a particular nucleus. Figure 3 shows an X-band spectrum of X-irradiated and ${ }^{15} \mathrm{~N}$ enriched polycrystalline MMP (solid line). A remarkable change was observed in the line shape and it was confirmed that the ESR center is associated with nitrogen. In addition, the spectrum of polycrystalline MMP in which ${ }^{14} \mathrm{~N}$ and ${ }^{15} \mathrm{~N}$ were equally abundant was exactly the weighted sum of the spectra for ${ }^{14} \mathrm{~N}$ and ${ }^{15} \mathrm{~N}$ enriched samples. This fact indicates that the center is associated with a single nitrogen.

To examine the effect of anisotropy of $\tilde{g}$-tensor on the line shape, K-band measurements were carried out. Figure 4 (b) shows the K-band spectrum of X-irradiated polycrystalline MMP. It was noticed that a set of absorption consisting of four shoulders indicated by the arrows shifted to lower field compared with the X-band spectrum (Fig. 4 (a)) without changing the splitting width. Thus, the center was found to have axially symmetric $\widetilde{g}$-tensor.

As clearly seen in Fig. 4, the features in the Xand K-band spectra are classified into four groups, each consisting of four component lines with the completely identical splitting pattern. This suggests that the spectra consist of the isotropic hf doublets due to two nuclei having

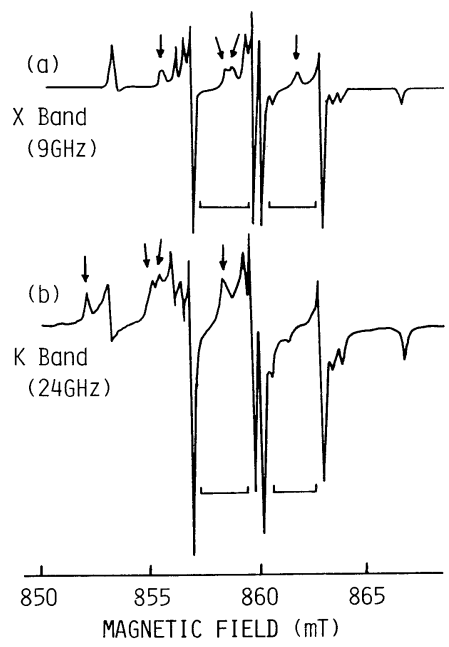

Fig. 4. K-band ESR spectrum of X-irradiated polycrystalline magnesium metaphosphate. The measurement was done at RT. X-band spectrum is also shown for comparison. Note that the shoulders labeled by arrows are shifted in harmony with each other. nuclear spin of $1 / 2 .{ }^{31} \mathrm{P}$ and ${ }^{1} \mathrm{H}$ are the possible candidates. Deuterized glasses were similarly treated, but substantial change was not observed in the spectrum. Further, ESR spectrum of $\mathrm{NH}_{2}$ radical ${ }^{16,17)}$ is distinguishable from above mentioned 5-line spectrum. Thus, it was inferred that the remaining two hf interactions can be attributed to two ${ }^{31} \mathrm{P}$ nuclei.

Taking account of the facts described above, we carried out computer simulation for the crystalline samples to estimate the ESR parameters of the center. To simplify simulation procedure, we took two assumptions;

(1) The high field first order approximation is valid, since the magnitude of the roughly estimated hf splittings are far smaller than $h \nu$.

(2) The principal axis systems of the $\tilde{g}$ tensor and the hf tensor of $\mathrm{N}$ are the same with each other. The hf tensors of two $\mathrm{P}$ nuclei are treated to be isotropic; $\boldsymbol{A}_{\mathrm{p}}=A_{\mathrm{p}}|\mathbf{1}|$

Then, the spin-Hamiltonian is given by

$$
\mathscr{Z}=\beta \cdot \boldsymbol{S} \cdot \tilde{\boldsymbol{g}} \cdot \boldsymbol{H}+\sum_{i=1}^{3} \boldsymbol{S}_{i} \cdot \boldsymbol{A}_{i} \cdot \boldsymbol{I}_{i}
$$

where the symbols have their usual meaning. The suffix $i(i=1,2,3)$ in the second term of the right hand side of Eq. (1) refers to one of the hf tensors, $\boldsymbol{A}_{1}$ for ${ }^{14} \mathrm{~N}$ or ${ }^{15} \mathrm{~N}, \boldsymbol{A}_{2}$ and $\boldsymbol{A}_{3}$ for ${ }^{31} \mathrm{P}$. Employing the high field first order approximation, the resonance field is given by

$$
H=\left(h \nu-K_{1} m_{\mathrm{I} 1}-K_{2} \mathrm{~m}_{\mathrm{I} 2}-K_{3} m_{\mathrm{I} 3}\right) / g \beta
$$

where

$$
\begin{aligned}
g= & \left\{\left(g_{x} \sin \theta \cdot \cos \phi\right)^{2}+\left(g_{y} \sin \theta \cdot \sin \phi\right)^{2}\right. \\
& +\left(g_{z} \cos \theta\right)^{2\}_{1}^{1 / 2}} \\
K_{i}= & \left(A_{x i}^{2} g_{x}^{2} l^{2}+A_{y i}^{2} g_{y}^{2} m^{2}+A_{z i}^{2} g_{z}^{2} n^{2}\right)^{1 / 2} / g(4)
\end{aligned}
$$

Therefore the powder pattern $S_{\mathrm{c}}(H)$, which is the ensemble of the absorptions due to a center randomly orientating with respect to $\boldsymbol{H}$, is calculated to be

$$
\begin{aligned}
S_{\mathrm{c}}(H)= & \int_{0}^{2 \pi} \int_{0}^{\pi} I(H) \\
& \cdot f\left\{H-H^{\prime}(\theta, \phi)\right\} \sin \theta \mathrm{d} \theta \mathrm{d} \phi
\end{aligned}
$$

where $I(H)$ and $f$ stand for the transition probability and line shape function such as Gaussian or Lorentzian.

Figure 5 shows stepwisely the generation of the observed powder pattern of MMP. The skewed absorption due to the anisotropic $\widetilde{g}$-tensor (the top in Fig. $5(\mathrm{a}))$ is transformed into the complex derivative spectrum (the bottom in Fig. 5(a)) through the anisotropic hf interaction of ${ }^{14} \mathrm{~N}(\mathrm{I}=$ $1)$. The pattern produced by the anisotropic $\widetilde{g}$ and ${ }^{14} \mathrm{~N}$ hf-tensors is further splitted into four by hf 

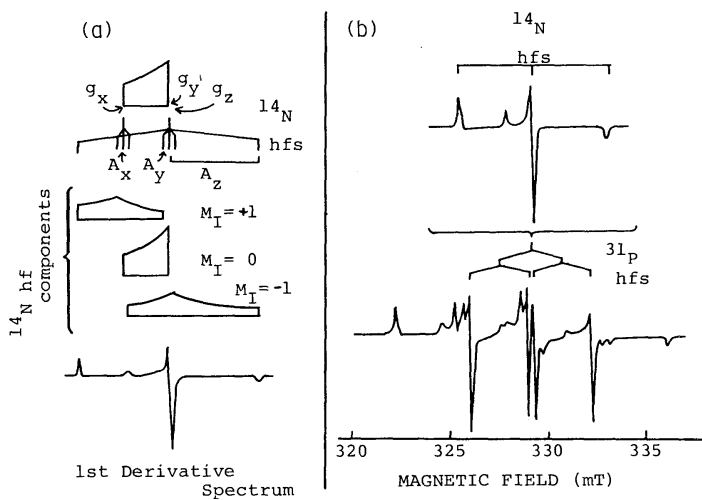

Fig. 5. Powder patterns of nitrogen associated hole center. In (a) only the hyperfine structure due to ${ }^{14} \mathrm{~N}$ was considered. The bottom spectrum was the sum of three hf component lines $\left(M_{\mathrm{I}}= \pm 1\right.$ and 0$)$. In (b) the ${ }^{14} \mathrm{~N}$ hfs was further splitted by two ${ }^{31} \mathrm{P}$ nuclei with $\mathrm{I}=1 / 2$.

interactions due to two ${ }^{31} \mathrm{P}$ nuclei as given in Fig. 5(b). The hf coupling interactions are assumed to be isotropic and slightly different each other. The best fitted curves to the experimental traces are shown in Fig. 2(b), (c) and Fig. 3 (dashed lines). The ESR parameters used in the calculations are listed in Table 2. The agreement between the calculated and observed is quite satisfactory. The ratio of the isotropic component $\left(A_{\text {iso }}\right)$ of hf coupling of ${ }^{14} \mathrm{~N}$ and ${ }^{15} \mathrm{~N}$, given by $\left(A_{x}\right.$ $\left.+A_{y}+A_{z}\right) / 3$, almost agreed with the ratio of free atomic values ${ }^{14} \mathrm{~N} ; 55.2 \mathrm{mT}$ and ${ }^{15} \mathrm{~N} ; 77.5 \mathrm{mT}$.

From the estimated parameters, spin density on $2 \mathrm{~s}$ - and $2 \mathrm{p}$-orbital of nitrogen was calculated by using Eqs. (6) and (7), respectively :

$$
\begin{aligned}
& C_{\mathrm{S}}^{2}=A_{\text {iso }} / A_{\mathrm{S}} \\
& C_{\mathrm{P}}^{2}=A_{\text {aniso }} / A_{\mathrm{P}}
\end{aligned}
$$

where $A_{\text {iso }}$ and $A_{\text {aniso }}$ represent the isotropic and anisotropic terms in the hf tensor of nitrogen, and $A_{\mathrm{S}}$ and $A_{\mathrm{P}}$ are those of free atomic nitrogen, respectively. The total density of the unpaired electron on nitrogen was calculated to be about $70 \%$ and the unpaired electron was found to be localized mostly on a nitrogen. The hyperfine coupling constant of two ${ }^{31} \mathrm{P}$ is comparable to that of $\mathrm{POHC}$, and two phosphorus atoms are considered to be bonding directly to the central nitrogen.

\subsection{Hole trapped or electron trapped center?}

In this subsection we discuss that the center responsible for the 5-line is an electron- or hole-trapped center. Firstly the effect of electron scavengers is examined. Phosphorous electron center described in section 3.1 was not detected in the spectra of $\gamma$-irradiated SMP glasses doped with a few amount of $\mathrm{Cd}^{2+}$ or $\mathrm{Ag}^{+}$, instead the formation was observed of the electron trapped center, $\mathrm{Cd}^{+}$or $\mathrm{Ag}^{018), 19}$. Figure 6 shows an ESR spectrum of SMP glass doped with $1 \mathrm{~mol} \% \mathrm{CdO}$ measured after $\gamma$-irradiation at $77 \mathrm{~K}$. The absorption near about $450 \mathrm{mT}$ is attributed to the superimposed hf structures of ${ }^{11} \mathrm{Cd}^{+}(\mathrm{N} . \mathrm{A} .=$ $12.86 \%)$ and ${ }^{113} \mathrm{Cd}^{+}($N. A. $=12.34 \%)$. As seen in the figure, phosphorus electron center which should be observable at the indicated magnetic fields was absent, but POHC and the nitrogen associated center were still survived (bottom trace). These observations suggest that a nitrogen

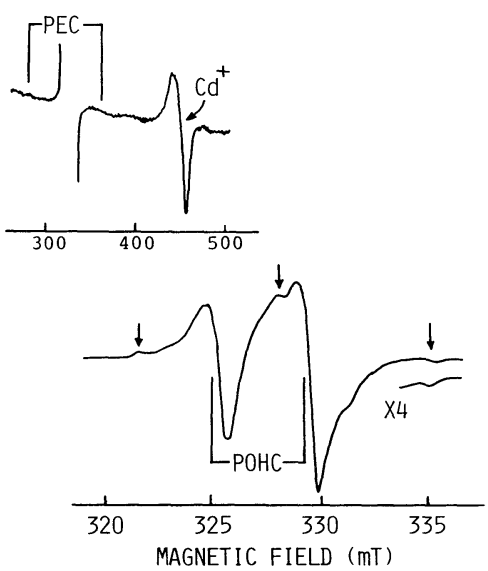

Fig. 6. X-band ESR spectrum of sodium metaphosphate glass doped with $1 \mathrm{~mol} \% \mathrm{CdO}$ after $\gamma$-irradiated at $77 \mathrm{~K}$. The absorptions indicated by arrows are due to nitrogen associated hole center. The hf absorption of $\mathrm{Cd}^{+}$was shown in the upper portion.

Table 2. ESR parameters of $\mathrm{N}$-associated hole center used in the computer simulation. Two $\mathrm{P}$ atoms are

\begin{tabular}{|c|c|c|c|c|c|c|c|c|c|c|c|c|}
\hline & & \multicolumn{3}{|c|}{$\mathrm{g}$-tensor } & \multicolumn{2}{|c|}{$\begin{array}{l}\text { hf-tensor } \\
\text { of } \mathrm{P}_{1}(\mathrm{~m} \mathrm{~T})\end{array}$} & \multicolumn{2}{|c|}{$\begin{array}{l}\text { hf-tensor } \\
\text { of } \mathrm{P}_{2}(\mathrm{mT})\end{array}$} & \multicolumn{2}{|c|}{$\begin{array}{l}\text { hf-tensor } \\
\text { of }{ }^{14} \mathrm{~N}(\mathrm{mT})\end{array}$} & \multicolumn{2}{|c|}{$\begin{array}{l}\text { hf-tensor } \\
\text { of }{ }^{15} \mathrm{~N}(\mathrm{mT})\end{array}$} \\
\hline & & $g_{x}$ & $g_{y}$ & $g_{z}$ & $\mathrm{~A}_{\mathrm{x}} \quad \mathrm{A}_{\mathrm{y}}$ & $\mathrm{A}_{z}$ & $\mathrm{~A}_{\mathrm{x}} \quad \mathrm{A}_{\mathrm{y}}$ & $\mathrm{A}_{z}$ & $\mathrm{~A}_{\mathrm{x}}$ & $\mathrm{A}_{\mathrm{z}}$ & $\mathrm{A}_{\mathrm{x}} \quad \mathrm{A}$ & $\mathrm{A}_{\mathrm{z}}$ \\
\hline Poly- & SMP & 2.0076 & 2.0031 & 2.0035 & $2.92 \quad 2.78$ & 2.92 & $2.92 \quad 2.78$ & 2.92 & $-0.20-0.20$ & 3.54 & & \\
\hline Crystalline & MMP & 2.0128 & 2.0044 & 2.0042 & $2.93 \quad 2.83$ & 2.83 & 3.223 .11 & 3.22 & $-0.20-0.20$ & 3.66 & $0.28 \quad 0.28$ & 5.14 \\
\hline Glassy & SSP & 2.0087 & 2.0047 & 2.0039 & $2.87 \quad 2.97$ & 2.78 & $2.77 \quad 2.67$ & 2.78 & $-0.20-0.20$ & 3.70 & & \\
\hline
\end{tabular}
distinguished by the subscript. 


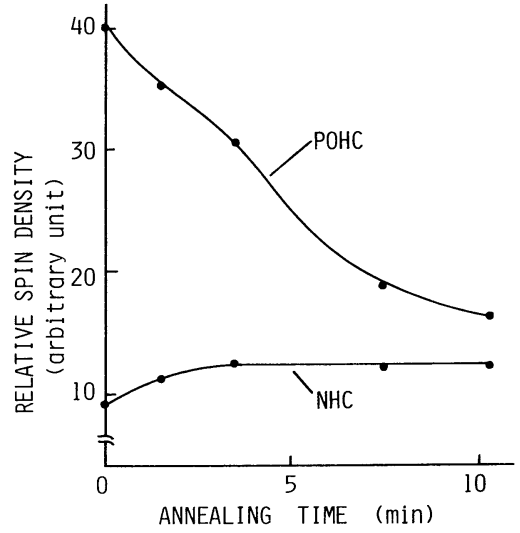

Fig. 7. The decay of the intensity of POHC signal and the rise of 5-line intensity with annealing time at room temperature.

associated center is formed by trapping a hole on a nitrogen. This view was further supported by detecting the hole transfer process from $\mathrm{POHC}$ to the nitrogen associated center on annealing at higher temperatures. Figure 7 shows the decay of the intensity of POHC signal and the rise of 5-line intensity with annealing time at room temperature. As seen in Fig. 7, the hole transfer from $\mathrm{POHC}$ to $\mathrm{N}$-associated center really occurs in the initial stage of the annealing. The decay of POHC signal continues after the initial transfer. This means that the nitrogen associated center has higher stability than $\mathrm{POHC}$ at this temperature $(300 \mathrm{~K})$.

Secondly, we made an additional experiment to confirm this conclusion. The nitrogen associated center and a phosphorous electron center were simultaneously generated in the deep UVirradiated $\left(190 \mathrm{~nm}^{-}\right)$SMP glasses. The simultaneous formation of these centers implies that a positive hole is trapped on a nitrogen and a released electron from the nitrogen is trapped on a phosphorous on the irradiation. This view will be discussed more detail in section 3.5. Hereafter the center will be abbreviated to as $\mathrm{NHC}$ (nitrogen hole center).

\subsection{Structural models of NHC and its pre- cursor}

Firstly, we consider a structural model of NHC. We propose the structural model of NHC as that shown in Fig. 8 (i), in which an unpaired electron occupies the non-bonding orbital on the nitrogen, which is orientating nearly vertical to the $\mathrm{P}-\mathrm{N}-\mathrm{P}$ plane. The planar structure is favored when considering that the anisotropic hf (i)
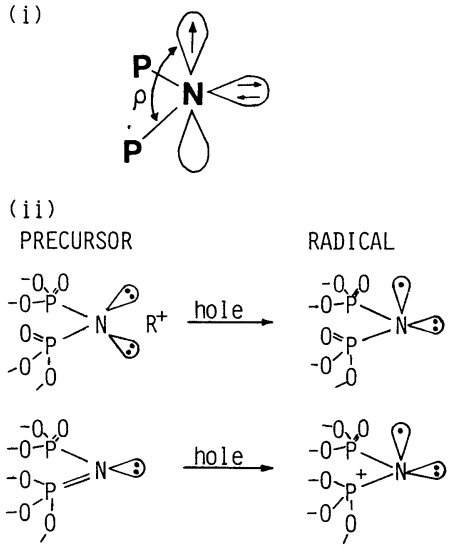

Fig. 8. ( i ) Model of the nitrogen associated hole center. (ii) Possible models of the precursor for $\mathrm{N}$-associated hole center and structure relaxation upon hole-trapping.

coupling interaction of ${ }^{14} \mathrm{~N}(\mathrm{I}=1,0.2 \mathrm{mT}$ to 3.6 $\mathrm{mT}$ ) are very similar to those of the radicals having a structure of the type $R_{3} N^{16), 20 \text {, 23) }}$ rather than a trigonal pyramidal structure of $\mathrm{R}_{3} \mathrm{~N}^{21 \text {-23) }}$. Two $\mathrm{P}$ atoms are likely to be bonded directly to the central nitrogen, because the isotropic hf coupling constant of ${ }^{31} \mathrm{P}(\mathrm{I}=1 / 2, \cong 3.0 \mathrm{mT})$ was comparable to that of $\mathrm{PO}_{4}^{2-}$ radicals ${ }^{24)}$ or $\mathrm{POHC}^{11)-141}$ in which a phosphorous atom is bonded to the hole trapped oxygen. The angle defect orbital-N-P labeled by $\rho$ was calculated to be $\cong 90^{\circ}$ by using the following equation ${ }^{25)}$,

$$
\tan \rho=\left\{2\left(1+\frac{A_{\text {aniso }}}{A_{\mathrm{P}}} \frac{A_{\mathrm{S}}}{A_{\text {iso }}}\right)\right\}^{1 / 2}
$$

Secondly, we discuss the possible models of the precursor of NHC. Two models are displayed in Fig. 8 ( ii ). In the first model (the upper one) two equivalent phosphorous atoms are bonded to the negatively charged nitrogen having two lone pairs and the charge is compensated by a sodium ion. When a hole is trapped on one of the lone pair of the nitrogen, a structural change occurs around the nitrogen, from tetrahedral to planar structure. In another model (bottom one) two phosphorous atoms are also neighboring, but one of them forms $\pi$-bond with the nitrogen having one lone pair. Apparently, NHC seems to be formed by breaking the $\pi$-bond. This photochemical reaction is considered to consist of two stages; the first is trapping a hole on the lone pair of the nitrogen and the second is the electron transfer from $\mathrm{P}$ to $\mathrm{N}$. This results in the model structure in which phosphorus atom has an excess positive charge after releasing a $\pi$-electron. A structural change upon trapping a hole is essential 
as an elongation of the $\mathrm{P}-\mathrm{N}$ bond.

The upper model is analogous to the proposed structure for $\equiv \mathrm{Si}-\dot{\mathrm{N}}-\mathrm{Si} \equiv$ radical in alkali silicate glass, which was formed by X-or UV-irradiation at above $200 \mathrm{~K}^{5}$. As ascribed later, $\mathrm{NHC}$ was also formed by UV-irradiation at even $77 \mathrm{~K}$. At this temperature, energy required for the upper process was too large to form NHC. Thus, the lower process was energetically more favorable than the upper process. In addition, Friebele et al. ${ }^{26}$ reported that $\equiv \mathrm{Si}-\mathrm{N}-\mathrm{Si} \equiv$ radical was found in $\mathrm{X}$-irradiated $\mathrm{SiO}_{2}$ film prepared by rf sputtering in $\mathrm{Ar}-\mathrm{N}_{2}$ atmosphere. Therefore the presence of sodium ion as a charge compensator is not always needed and the upper model is excluded from this reason.

\subsection{Donor property of incorporated nitrogen}

As mentioned in section 3.4, NHC could be formed by deep UV(190 nm-)-irradiation at above $77 \mathrm{~K}$. Figure 9 shows an ESR spectra of SMP glass generated by UV-irradiation at $77 \mathrm{~K}$ for $2 \mathrm{~h}(\mathrm{a})$ and $\gamma$-irradiated(b). Although the total spin concentration of the former was smaller than the latter about one order of magnitude, the relative intensity between $\mathrm{NHC}$ and $\mathrm{POHC}$ was reversed, i. e., $\mathrm{NHC}$ was dominant in UV excited spectrum, while POHC was dominant in $\gamma$ irradiated spectrum. This fact suggests that (1) absolute intensity of induced center depends on the photon energy and ( 2 ) nitrogen forms shallow energy level compared with oxygen. Therefore, upon $\gamma$-irradiation, both $\mathrm{NHC}$ and POHC are formed and the intensity ratio of these centers are determined by the fraction of their precursors,

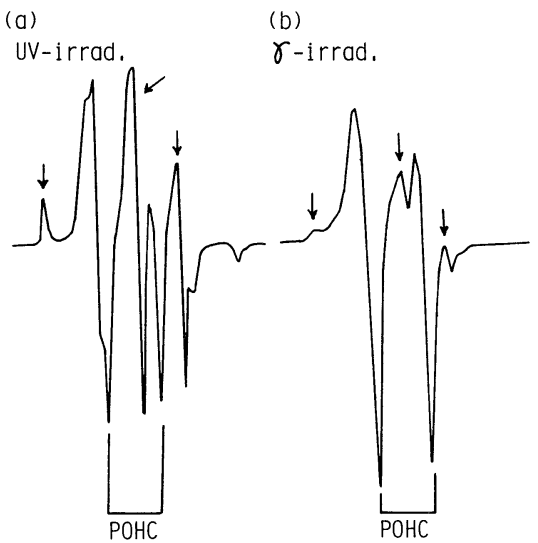

Fig. 9. ESR spectra of sodium metaphosphate glass after UV-irradiation (a) and $\gamma$-irradiation (b) at $77 \mathrm{~K}$. The arrows indicate the absorption due to NHC. The spectrum of $\gamma$-irrad. glass was obtained with reduced gain $(\times 1 / 10)$. non-bridging oxygen and the bridging nitrogen. Upon UV-irradiation, NHC is selectively formed since the photon energy of UV light is not enough to form POHC.

Figure 10 shows the changes in ESR spectrum of SMP glass with UV-irradiation time at $77 \mathrm{~K}$. As seen in the right hand side of the figure, both $\mathrm{NHC}$ and $\mathrm{POHC}$ were growing up with time but the rate of growth of $\mathrm{NHC}$ is larger than that of POHC. Besides this, as seen in the left hand side, PEC was also growing up with irradiation time. The simultaneous formation of both an electron center (PEC) and a hole center (NHC) indicates that the nitrogen acts as a donor and phosphorus as an acceptor; upon UV-irradiation an electron is released from the non-bonding level of nitrogen and trapped by a phosphorus atom.

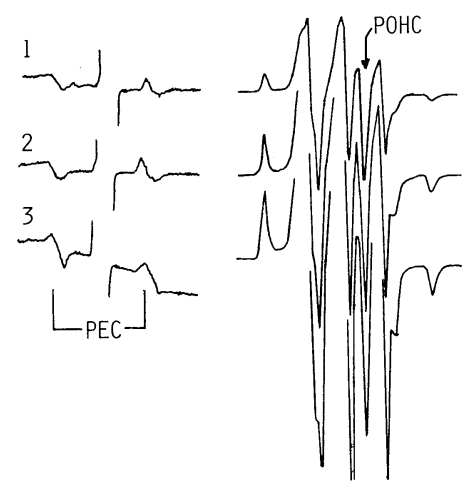

Fig. 10. Growth of NHC and PEC with UV-irradiation time.

1: After $30 \mathrm{~min}, 2:$ After $60 \mathrm{~min}, 3:$ After $120 \mathrm{~min}$

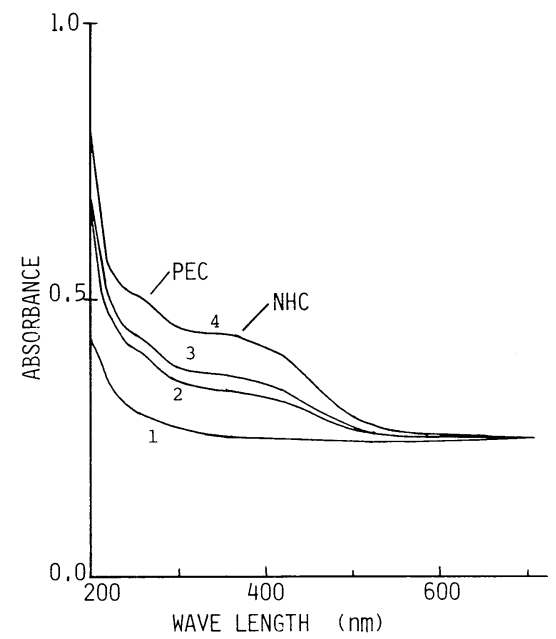

Fig. 11. Changes in the absorption spectrum of sodium metaphosphate glass with UV-irradiation time.

1 : Before irradiation, 2: After $20 \mathrm{~min}, 3:$ After $40 \mathrm{~min}$, 4: After $120 \mathrm{~min}$ 
The simultaneous formation of PEC and $\mathrm{NHC}$ was further confirmed by optical measurements. Figure 11 shows the changes in optical absorption spectrum of SMP glass with UV-irradiation time at room temperature. At RT the intensity of $\mathrm{POHC}$ is expected to be very small. The bands near $250 \mathrm{~nm}$ attributable to $\mathrm{PEC}^{11}$, was growing up with time and this was in accordance with the result of ESR. The glass was transparent before irradiation and colored yellow upon the irradiation. The wide band near $350 \mathrm{~nm}$ was responsible for the coloration and was supposed to arises from NHC, since the band of POHC in SMP glasses was reported to be present at near $500 \mathrm{~nm}^{27,28)}$ and the $350 \mathrm{~nm}$ band was also growing up with time in harmony with the increase in ESR intensity of NHC. Thus, the donor property of incorporated nitrogen was experimentally evidenced.

3. 6 Chemical bonding state of incorporated nitrogen and its effect on "strengthening" of glass network

We have discussed structural aspects of NHC so far. In this subsection we consider the role of incorporated nitrogen in strengthening glass network.

The simulation of the experimental spectra of $\mathrm{NHC}$ in the glass samples is ongoing to estimate the distribution of ESR parameters which reflects site to
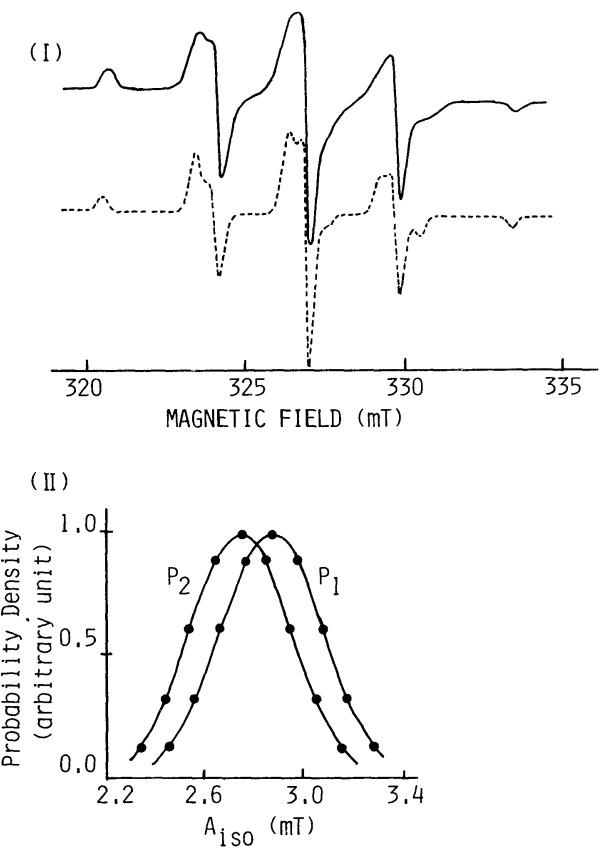

Fig. 12. ( I ) Result of computer simulation for sodium metaphosphate glass (dashed line).

( II ) Distribution function of $A_{\text {iso }}$ of two ${ }^{31} \mathrm{P}$ used in the simulation. site structural distribution of the center. Result of the simulation was shown in Figure 12( I )(dashed line). This was obtained by assuming a Gaussian distribution in $A_{\text {iso }}$ of two ${ }^{31} \mathrm{P}$, shown in Fig. 12 ( II ). The agreement between the observed and calculated is still slightly unsatisfactory. However, if we introduce an additional Gaussian distribution in $A_{\text {iso }}$ of $\mathrm{N}$ with the width of $1 \%$, it gives rise to far broader signal than the observed. The distribution in the hf parameters can be transformed to that of the structural distribution by using an equation like Eq. ( 8 ). The width of site to site structural distribution around a particular atom in glass reflects its "chemical rigidity" ${ }^{30}$; glass constituting atoms are in competition with each other in taking their favorable coordination on a cooling process from a melt to glass. Atoms making strong bonds with its neighbors show narrow distribution and those with weak bonds have highly distorted coordination structure.

The estimated distribution in $\rho$ was calculated to be less than $1^{\circ}$. The distributions of the ESR parameters and bond angles for nitrogen should be compared with those for bridging oxygen hole center $(\mathrm{OHC})$. There has been no directly comparable data, but the distribution of $\mathrm{Si}-\mathrm{O}-\mathrm{Si}$ bond angle was estimated by $\mathrm{X}$-ray analysis ${ }^{29}$. The comparison showed that the local structure around the incorporated nitrogen is far rigid than that around oxygen. It has been reported ${ }^{311}$ that the ratio of magnitudes of the induced deformations around two different types of cation upon application of high pressure to glass is proportional to ratio of the structural distributions around the cations caused by changing chemical composition. This means that the chemically rigid coordination sphere is also rigid for mechanical stress, and the relation may be termed as "mechanical and chemical equivalency". The narrow width of the distribution in $A_{\text {iso }}$ of $\mathrm{N}$ implies that the coordination around nitrogen is chemically rigid. On an analogy, the micro-rigidity around the incorporated nitrogen would contribute to the improvements of mechanical properties of oxynitride glasses.

\section{Summary}

In a present work $\gamma$-and photon-induced ESR centers in polycrystalline and glassy metaphosphates containing nitrogen were investigated with ESR. Four paramagnetic defects were found and identified by analyzing their ESR line shapes. One of these centers is associated with single nitrogen and it is a positive hole trapped on a nitrogen (NHC). The conclusions are: 
(1) NHC has a planar structure of P-N-P in which an unpaired electron is mainly locating on nitrogen.

(2) NHC is formed by trapping a hole on the lone pair of bridging nitrogen upon $\gamma$-or UVirradiation.

(3) The incorporated nitrogen acts as an electron donor, whereas phosphorus as an acceptor upon the irradiation.

(4) The "strengthening" of glass network by incorporation of nitrogen is interpreted in terms of covalency of $\mathrm{P}-\mathrm{N}$ bond, which was estimated from the width of distribution in ESR parameters. The width reflects the micro-rigidity around the nitrogen.

Acknowledgment This work was in part supported by a Grantin-Aid for Scientific Research from the Japanese Ministry of Education, Science and Culture (Nos. 59550533 and 57470052).

\section{References}

1) R. E. Loehman, J. Non-Cryst., 56, 123-34 (1983).

2) E. L. Swarts and J.P. Pressau, J. Am. Ceram, Soc., 48, 333-38 (1965).

3) R.J. Araujo, "Treatise on Materials Science and Technology”, Ed. M. Tomozawa and R.H. Doremus, Academic Press, NY (1979) Vol.12, p. 91-122.

4) E. L. Swarts and L.M. Cook, 7 th Int. Congr. Glass, Brussel (1965).

5) J.H. Mackey, J.W. Boss and M. Kopp, Phys. Chem. Glasses, 11, 205-12 (1970).

6) Y. Watanabe, T. Kanazawa and H. Kawazoe, Proc. of Int. Conf., "Effects of Modes of Formation on the Structure of Glass", Nashville, 1984, to be published in J. Non-Cryst. Solids.

7) G. H. Frischat and O. B. Boschman, C. Zellerfeld and H. Mayer, Glastech. Ber., 51, 321 (1978).
8) R. A. Weeks and P.J. Bray, J. Chem. Phys., 48, 5-13 (1968).

9) H. Hosono, Y. Abe and H. Kawazoe, Proc. of Int. Conf., "Effects of Modes of Formation on the Structure of Glass", Nashville, 1984, to be published in J. Non-Cryst. Solids.

10) H. Hosono and Y. Abe, Yogyo-Kyokai-Shi, 93, 217-24 (1985).

11) D. L. Griscom, E. J. Friebele and K.J. Long, J. Appl. Phys., 54, 3743-62 (1983).

12) G. O. Krapetyan and D.M. Yudin, Fiz. Trerd. Tela (Kharkov), 3, 2827 (1961).

13) P. Beekenkamp, Philips Res. Rep. Suppl., 4, 1 (1966).

14) K.A. Akhmed-Sade, V.A. Zakrevskiil and D. M. Yudin, Fiz. Tuerd. Tela (Kharkov), 15, 1520 (1973).

15) D. M. Yudin, A. V. Shendrik, M. L. Petrovskaya and G. P. Nikolina, Fiz. Tverd. Tela., 15, 2636-40 (1973).

16) I. S. Ginns and M. C. R. Symons, J. Chem. S. Faraday II, 68, 631-37 (1972)

17) K. V.S. Rao, J. Chem. Soc. (A), 2163 (1971).

18) H. Imagawa, J. Non-Cryst. Solids., 1, 335-38 (1969).

19) H. Imagawa, Phys. Chem. Glasses, 10, 187-91 (1969).

20) A. Horsfield, J.R. Morton, J.R. Rowlands and D. H. Whiffen, Mol. Phys., 5, 241-50 (1962).

21) J.R. Rowlands, ibid., 5, 565-71 (1962).

22) T. Cole, J. Chem. Phys., 35, 1169-73 (1961).

23) P.W. Atkins and M.C.R. Symons, "The Structure of Inorganic Radicals", Elsevier Publishing Company (1967).

24) S. Subramanian, M. C. R. Symons and H. W. Wardale, J. Chem. Soc. (A), 1239-42 (1970).

25) Coulson, "Valence”, Oxford Univ. Press (1961).

26) E. J. Friebele, D. L. Griscom and T. W. Hickmott, Proc. of Int. Conf., "Effects of Modes of Formation on the Structure of Glass", Nashville, 1984, to be published in J. Non-Cryst. Solids.

27) A. Barkatt, M. Ottolenghi and J. Rabani, J. Phys. Chem., 76, 203 (1972)

28) A. Barkatt, M. Ottolenghi and J. Rabani, J. Phys. Chem., 77, 2857 (1973).

29) R. L. Mozzi and B.E. Warren, J. Appl. Cryst., 2, 164 (1969).

30) H. Kawazoe, H. Hosono, H. Kokumai, J. Nishii and T. Kanazawa, J. Non-Cryst. Solids, 40, 291-303 (1980).

31) H. Hosono, H. Kawazoe and T. Kanazawa, Solid State. Commum., 43, 769-71 (1982). 